\title{
Preface
}

\section{6th International Conference on New Frontiers in Physics 2017}

The conference series "New Frontiers in Physics" aims to promote scientific exchange and development of novel ideas in science with particular emphasis on interdisciplinarity. The main topics of the conference are high energy particle and nuclear physics, heavy ion physics, quantum optics and quantum entanglement, cosmology, astrophysics, gravity, mathematical physics.

The 6th International Conference on New Frontiers in Physics (ICNFP 2017) attracted more than 375 participants. During the conference 9 lectures, 376 oral presentations and 27 posters were given. The conference included 19 dedicated sessions, mini-workshops and events.

Physics Education and Outreach Activities at ICNFP 2017 were convened by Dr. Vladimir Gligorov (CNRS, France), Prof. Mina Katramatou (Kent State University, Kent, USA) and Dr. Malgorzata Kazana (NCPJ Warsaw, Poland). The activities included Masterclasses and Outreach lectures, Distinguished Public lecture in Greek by Prof. Jean Iliopoulos, Distinguished Public lecture in English by Prof. John Ellis, and Special Session on Physics Education and Outreach, convened by Prof. Mina Katramatou (Kent State University, USA). Cultural events included: Opera Gala and Concert of Sacred Music by Kalliopi Petrou (Soprano) and Stefano Menegus (piano); Classical Music concerts from Mikhail (tenor), Svetlana (Violin), Vladimir (Cello) Nor, Ruben Muradyan (piano), llia Krasovitsky (piano) took place during the conference. Four options for the Conference Excursion were provided on Sundays 20 and 27 August 2017 as well as the Conference Dinner on 23 August.

We would like to thank all the conference participants as well as the members of the International Advisory Committee, the Organizing Committee, the Organizing Institutes and Sponsors, the Great Arsenal of Chania for the organization of public events and outreach, and especially the hosting Orthodox Academy of Crete for the extremely warm atmosphere of the conference. We would also like to thank Vladimir Kovalenko from Saint Petersburg State University and the staff of "European Physical Journal Web of Conferences" for the help with publishing the proceedings.

Yakir Aharonov, Larissa Bravina and Sonia Kabana, 


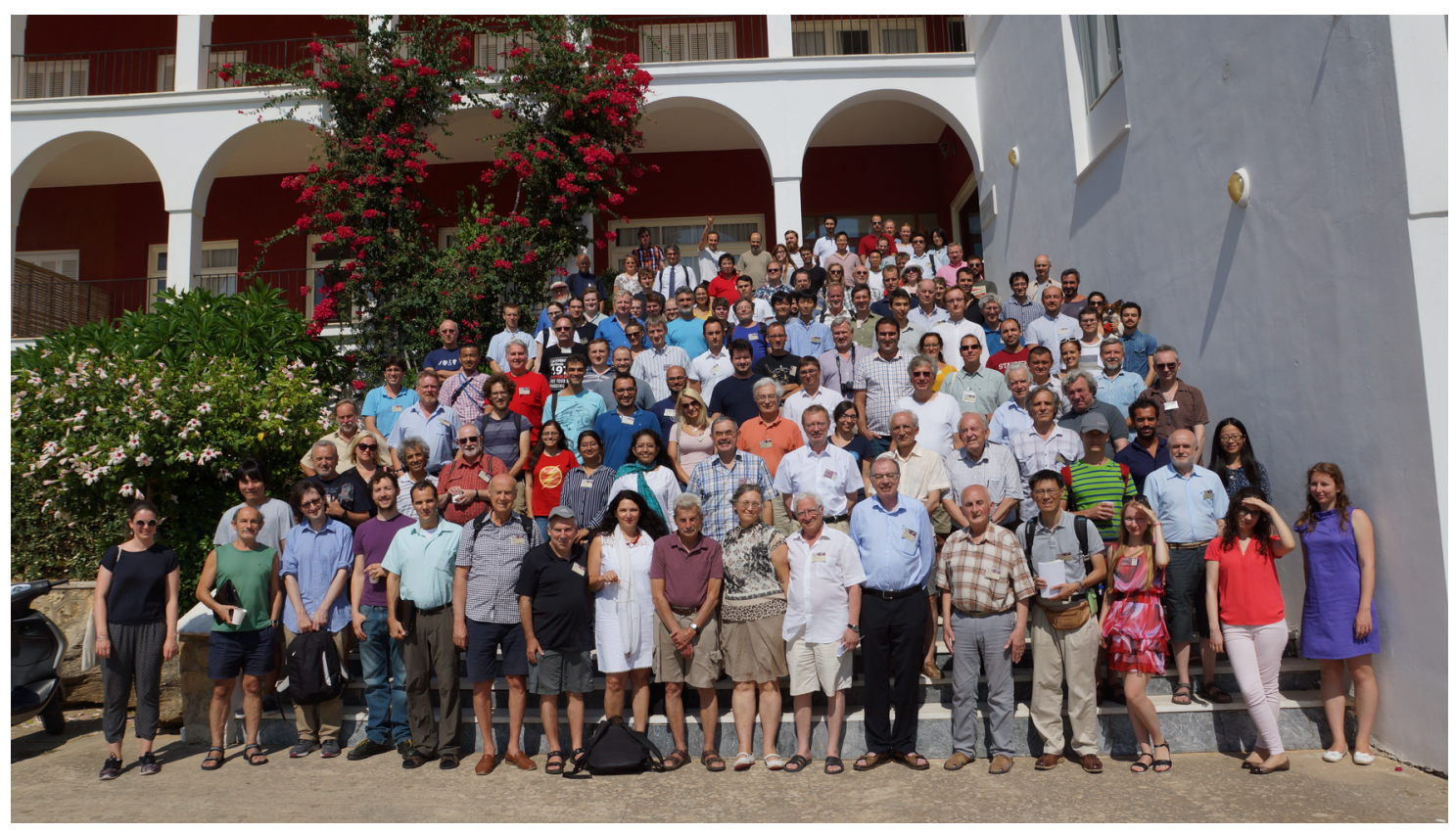

